\title{
Efficient production of soluble recombinant single chain Fv fragments by a Pseudomonas putida strain KT2440 cell factory
}

Dammeyer et al. 


\title{
Efficient production of soluble recombinant single chain Fv fragments by a Pseudomonas putida strain KT2440 cell factory
}

\author{
Thorben Dammeyer ${ }^{1 *}$, Miriam Steinwand ${ }^{2}$, Sarah-C Krüger ${ }^{1}$, Stefan Dübel ${ }^{2}$, Michael Hust ${ }^{2}$, Kenneth N Timmis ${ }^{1,3}$
}

\begin{abstract}
Background: Recombinant antibody fragments have a wide range of applications in research, diagnostics and therapy. For many of these, small fragments like single chain fragment variables (scFv) function well and can be produced inexpensively in bacterial expression systems. Although Escherichia coli K-12 production systems are convenient, yields of different fragments, even those produced from codon-optimized expression systems, vary significantly. Where yields are inadequate, alternative production systems are needed. Pseudomonas putida strain KT2440 is a versatile biosafety strain known for good expression of heterologous genes, so we have explored its utility as a cell factory for production of scFvs.
\end{abstract}

Results: We have generated new broad host range scFv expression constructs and assessed their production in the Pseudomonas putida KT2440 host. Two scFvs bind either to human C-reactive protein or to mucin1, proteins of significant medical diagnostic and therapeutic interest, whereas a third is a model anti-lysozyme scFv. The KT2440 antibody expression systems produce scFvs targeted to the periplasmic space that were processed precisely and were easily recovered and purified by single-step or tandem affinity chromatography. The influence of promoter system, codon optimization for P. putida, and medium on scFv yield was examined. Yields of up to $3.5 \mathrm{mg} / \mathrm{l}$ of pure, soluble, active scFv fragments were obtained from shake flask cultures of constructs based on the original codon usage and expressed from the Ptac expression system, yields that were 2.5-4 times higher than those from equivalent cultures of an E. coli K-12 expression host.

Conclusions: Pseudomonas putida KT2440 is a good cell factory for the production of scFvs, and the broad host range constructs we have produced allow yield assessment in a number of different expression hosts when yields in one initially selected are insufficient. High cell density cultivation and further optimization and refinement of the KT2440 cell factory will achieve additional increases in the yields of scFvs.

\section{Background}

Recombinant antibodies and antibody fragments are indispensable tools for research, diagnostics and therapy [1-5]. Complete and natively glycolsylated antibodies, like IgGs, needed for therapeutic purposes must thus far be produced in mammalian cells. However, although yields from mammalian cells tend to be good, production times and costs are high [6]. However, for many non-therapeutic applications, and also some therapeutic applications for which effector functions are not

\footnotetext{
* Correspondence: thorben.dammeyer@helmholtz-hzi.de 'Environmental Microbiology Laboratory, Helmholtz Centre for Infection Research, Inhoffenstr. 7, 38124 Braunschweig, Germany Full list of author information is available at the end of the article
}

necessary, antibody modules, such as single chain fragment variable (scFv) and fragment antigen binding (Fab) are sufficient $[7,8]$. Because of their lower costs and faster production cycles, microbial systems are more attractive than mammalian cell systems for the production of antibody fragments. The folding and export of scFvs in Gram-negative systems is usually more efficient than that of Fab fragments [9]. One problem with prokaryotic production systems is that expression levels of fragments of different antibodies tend to differ markedly $[10,11]$ and, in many instances, only synthetic, codonusage adapted, genes provide significant yields. The availability of a core suite of distinct efficient host-broad host range expression cloning vector systems, differing

\section{Biomed Central}


in their expression specificities, should enable determination of optimal production systems for different proteins.

Pseudomonas putida strain KT2440 is a metabolically versatile soil bacterium with considerable potential in a broad range of diverse industrial and environmental applications [12]. Its certification as a biosafety strain $[13,14]$, its ability to express a broad spectrum of foreign proteins at high levels and the availability of powerful customized tools for genetic analysis and manipulation [15], make KT2440 an important prokaryotic cell factory. These features suggest that it might be a useful production system for antibody fragments.

In this study, we have assessed the potential of KT2440 for the soluble production of different recombinant scFvs namely, the model murine anti-hen eggwhite lysozyme scFv, D1.3 [11,16-19], and two phage display-selected human scFvs: TOB5-D4 [[11], Al-Halabi et al. in preparation], directed against $\mathrm{C}$-reactive protein (CRP) [20], an inflammation indicator in human blood, and HT186-D11 [21], directed against mucin1 (MUC1), a diagnostic marker and potential therapeutic target of cancer [22,23].

\section{Results and Discussion}

\section{Expression plasmids and synthetic genes}

The key features of the antibody expression plasmids constructed in this study are shown in Table 1 . They were generated using new synthetic RK2 broad host range plasmid-based chassis developed by the group of Victor de Lorenzo (in preparation) carrying either the inducible Ptac [13,24] or TOL plasmid $x y l$ operon Pm $[25,26]$ promoters. We further modified the chassis by equipping it with the G10L ribosome binding site (RBS) with epsilon enhancer [27] and the Erwinia carotovora pelB leader sequence [28] to effect the export of expressed polypeptides to the periplasm. The scFv format consists of variable regions of the antibody heavy and light chains ( $\mathrm{VH}$ and VL, respectively), joined by a 15-25 amino acid linker [29]. Polynucleotide sequences encoding Myc-HIS 6 -Strep-Tag ${ }^{\circledR}$ II or $\mathrm{HIS}_{6}$-Myc-Strep-
$\mathrm{Tag}^{\circledR}$ II affinity tags were placed downstream of the VH-linker-VL coding sequences (Table 1) to facilitate purification and detection of the scFvs in western blots and enzyme-linked immunosorbent assays (ELISA). In addition, synthetic $\mathrm{scFv}$ genes were generated to assess the influence of codon usage adaptation on expression levels in P. putida (Table 1). The original scFv gene constructs were expressed from the Ptac promoter, whereas the synthetic gene constructs were expressed from either Ptac or Pm promoters (Table 1). Although synthetic codon usage adapted gene constructs of TOB5-D4 (anti-CRP) and HT186-D11 (anti-mucin1) scFvs were readily generated, for unknown reasons the equivalent version of D1.3 (anti-lysozyme) scFv could not be synthezised by the commercial supplier. For generation of the native sequence constructs, the RBS and Strep-tag ${ }^{\circledR}$ II were added using primer overhangs.

\section{Affinity isolation of scFvs}

Different combinations of cell lysis and affinity purification strategies were tested in order to determine a rapid, simple isolation/purification protocol. Purification of hexahistidine-tagged scFvs from clarified whole cell extracts by immobilized metal ion affinity chromatography (IMAC) resulted in a protein mixture containing three major species between $30-50 \mathrm{kDa}$, of which the mid band was confirmed by $\mathrm{N}$-terminal sequencing to be the scFv. The addition of a second affinity chromatography on Strep-Tactin Superflow in series (tandem) resulted in $\mathrm{scFv}$ fragments of high purity with no visible background in sensitively Coomassie Blue-stained SDSPAGE (data not shown). Single step purification on Strep-Tactin Superflow resin in gravity flow columns, however, proved sufficient for most purposes, including yield determination. This single-step protocol yielded scFv fragments with a purity of $\sim 95 \%$. Incubation of the purified fragments for 16-24 h on ice, followed by at least one freeze thaw cycle in elution buffer, did not cause significant degradation of the scFvs (Figure 1). Lysis of cells by sonication or use of the bacterial protein extraction reagent (B-Per, Thermo fisher scientific),

Table 1 Properties of the RK2-based broad-host range plasmid constructs with the Ptac/laclq (pSEVAlac) or Pm/xy/S (pSEVAxyl) promoter/regulator gene systems used in this study

\begin{tabular}{|c|c|c|c|c|c|}
\hline Construct & scFv specificity & Promoter & Affinity-tags & codon optimization $^{1}$ & $\% \mathrm{GC}^{2}$ \\
\hline pSEVAlacD1.3n & hen egg-white lysozyme & Ptac & HIS6/Myc/Strep-tag ${ }^{\circledR} \|$ & - & 52,3 \\
\hline pSEVAlacTOB5-D4n & human CRP & Ptac & Myc/HIS6/Strep-tag ${ }^{\mathbb{R}} \|$ & - & 55,0 \\
\hline pSEVAlacTOB5-D4s & human CRP & Ptac & Myc/HIS6/Strep-tag ${ }^{\circledR} \|$ & Jcat/Eurofins MWG Operon & 68,3 \\
\hline pSEVAxyITOB5-D4s & human CRP & $P m$ & Myc/HIS6/Strep-tag ${ }^{\mathbb{R}} \|$ & Jcat/Eurofins MWG Operon & 68,3 \\
\hline pSEVAlacHT186-D11n & human mucin1 & Ptac & HIS6/Myc/Strep-tag ${ }^{\circledR} \|$ & - & 57,8 \\
\hline pSEVAlacHT186-D11s & human mucin1 & Ptac & HIS6/Myc/Strep-tag ${ }^{\mathbb{R}} \|$ & GeneOptimizer $^{\mathbb{R}} /$ GENEART & 67,6 \\
\hline pSEVAxylHT186-D11s & human mucin1 & $P m$ & HIS6/Myc/Strep-tag ${ }^{\circledR} \|$ & GeneOptimizer $^{(\mathbb{R}} /$ GENEART & 67,6 \\
\hline
\end{tabular}

${ }^{1}$ Synthetic scFv determinants with optimized codon usage: - indicates the original scFv sequence, Jcat/Eurofins MWG Operon and GeneOptimizer ${ }^{\mathbb{R}} /$ GENEART indicates a codon adaptation tool and a supplier; ${ }^{2} \% \mathrm{GC}$ content of the scFv coding sequence. 


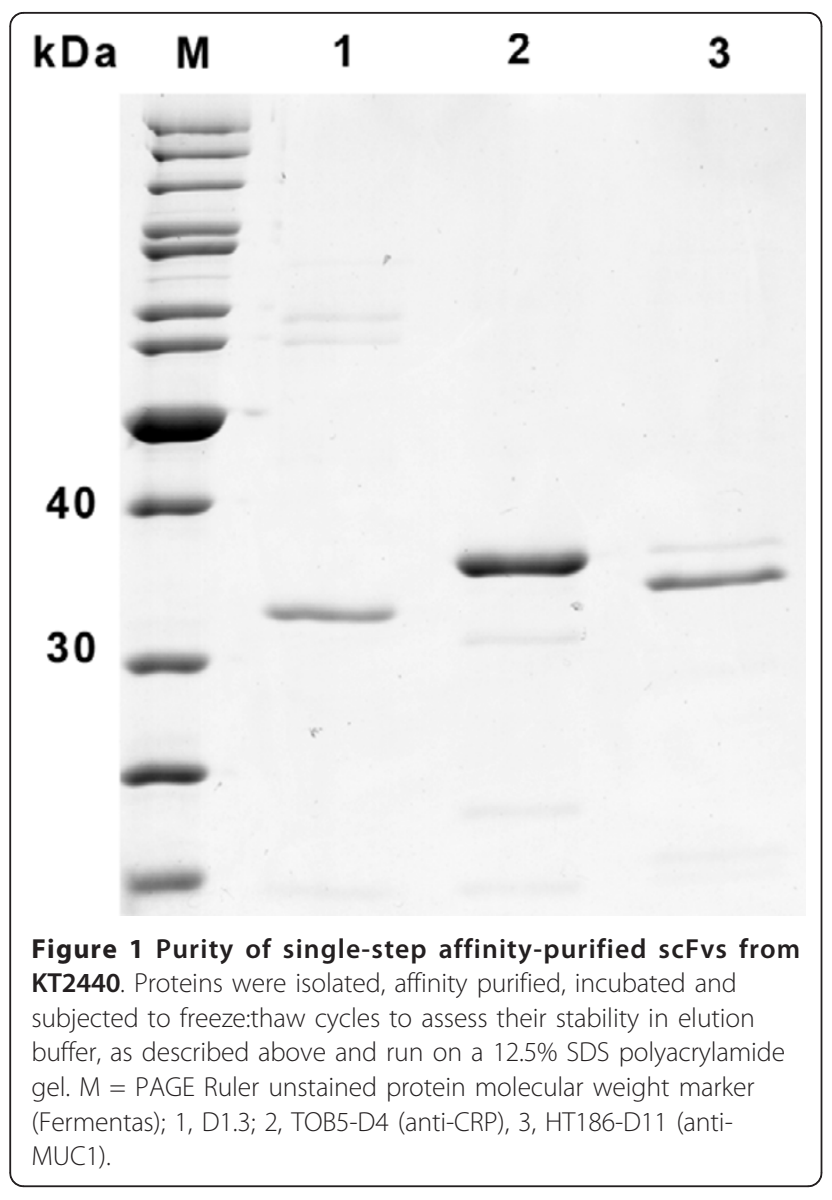

or both in combination, gave similar results, which is perhaps not surprising, given that the scFvs are targeted to the periplasmic space. Moreover, purification of selectively released periplasmic proteins (see below) by single step Strep-Tactin Superflow chromatography resulted in a purity comparable to those obtained by the tandem strategy.

\section{scFv yield optimization Induction}

Two transcriptional expression systems based on the Ptac and $P m$ promoters, that are widely used to express heterologous genes, were assessed for their efficacy in $\mathrm{scFv}$ production by KT2440 in otherwise identical RK2 plasmid-based expression constructs (Table 1). In the case of the TOB5-D4s and HT186-D11s scFvs, yields from the Ptac promoter constructs were more than twice those from the Pm promoter constructs. Optimal yield conditions determined for Ptac constructs were $3 \mathrm{~h}$ induction by $1 \mathrm{mM}$ IPTG at $30^{\circ} \mathrm{C}$ in LB-medium, which gave yields of $1.5 \mathrm{mg} / \mathrm{l}$ for the D1.3 scFv, $2.9 \mathrm{mg} / \mathrm{l}$ for the anti-CRP $\mathrm{scFv}$, and $3.6 \mathrm{mg} / \mathrm{l}$ for the HT186-D11 scFv (Figure 2; yield means of 3-6 individual expression experiments involving $100 \mathrm{ml}$ cultures agitated at $180 \mathrm{rpm}$, and

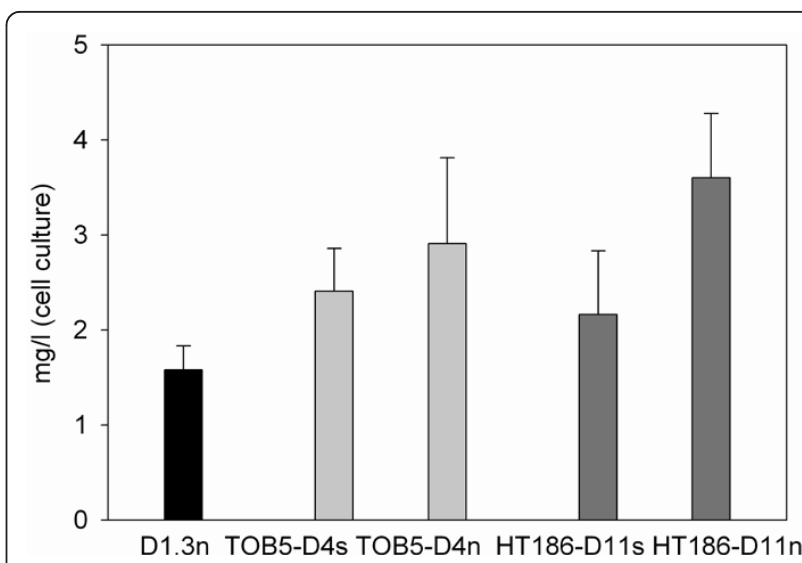

Figure 2 Yields of soluble scFvs from KT2440 constructs. Mean values and standard deviations are given of yields from single-step purified soluble scFvs obtained from 3-6 independent expression and purification experiments.

isolation by single step affinity purification on $1 \mathrm{ml}$ StrepTactin Superflow gravity columns). The influence of medium composition on yield was also assessed and it was found that yields decreased in the order: Terrific Broth (TB) > LB > M9 (15 mM succinate) > R2A (Figure 3), indicating that enriched, buffered media favour scFv production and that medium optimization has considerable potential for yield enhancement.

\section{Codon usage optimization}

KT2440 is an expression host with a high average GC content $(\sim 61.5 \%)$ and a codon usage preference distinct from those of the $\mathrm{scFv}$ determinants used in this study [14]. To assess to which extent adaptation of the scFv codons to those preferred by KT2440 could influence scFv yields, synthetic scFv determinants composed of the preferred codons were designed in silico, synthesized and tested in the expression systems. Although synthetic versions of the TOB5-D4 (anti-CRP) and HT186-D11 (anti-MUC1) scFv sequences were made, it was not possible to obtain a synthetic version of the D1.3 (antilysozyme) scFv (Table 1). For the two former scFvs, it was found that the yields $-2.4 \mathrm{mg} / \mathrm{l}$ for TOB5-D4s (anti-CRP) and $2.1 \mathrm{mg} / \mathrm{l}$ for HT186-D11s (anti-MUC1) (Figure 2) - were lower than those from the original constructs, so in these cases, codon usage optimization

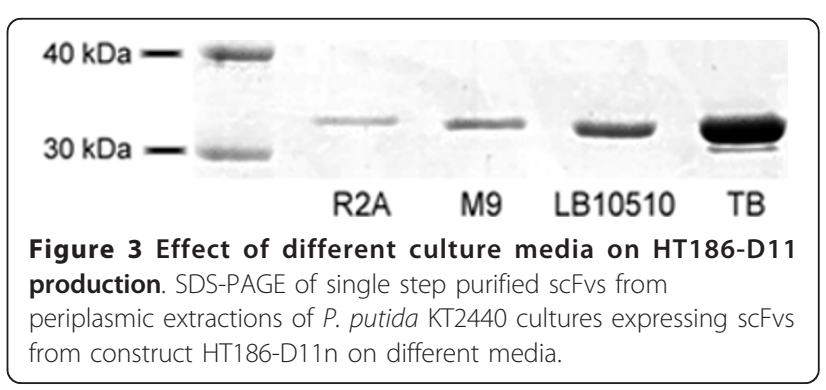


did not increase expression levels. This might reflect the ability of KT2440 to efficiently express a broad range of foreign genes, or limitation of higher levels of expression otherwise attainable due to the higher than normal (for KT2440) GC contents of the synthetic genes (Table 1), or sub-optimal mRNA secondary structures created by the changes [30].

The key question arising from these results is how the scFv yields obtained compare with those obtainable from existing expression systems. Unfortunately, pertinent information could not be found in the literature, and values that are available are not usable due to differences in antibody and/or experimental procedures followed. To obtain relevant information on this issue, we introduced the broad range constructs into the Escherichia coli expression strain BL21 (DE3). Yields of the TOB5-D4n and HT186-D11n scFvs from E. coli were 2.5 to 4 -fold lower than those from KT2440, and, as might be predicted, even lower in the case of the high GC synthetic genes (data not shown). Literature yields in $E$. coli for an anti-CRP scFv antibody of 0.55 $\mathrm{mg} / \mathrm{l}$ [31] and the D1.3 scFv antibody of $0.29 \mathrm{mg} / \mathrm{l}$ [10] lie within the same low range.

\section{Periplasmic export}

All genetic constructs were designed to create precise amino-terminal translational fusions of the $\mathrm{scFv}$-coding sequences with the $E$. carotovora pelB signal sequence to target the scFvs for secretion by the Sec pathway. For assessment of the efficiency of processing of the scFv fragments produced in KT2440, and their translocation to the periplasm, periplasmic fractions were isolated. This procedure generally gave $\mathrm{scFv}$ yields in the same range as, though with greater variability than, those obtained by whole cell lysis. To ascertain whether the increased variation in yield is due to incomplete release of periplasmic proteins during the isolation procedure or incomplete translocation to the periplasm, perhaps resulting from overloading of the secretion apparatus, Sec-mediated proteolytic cleavage of the pelB leader sequences of the scFvs was analyzed by electrophoretic separation followed by western blot detection of the C-terminal Strep-tag ${ }^{\circledR}$ II (Figure 4A). As expected, only fully processed scFvs were detected in periplasmic preparations, indicating that periplasmic scFvs are completely processed. In the case of proteins extracted from whole cells, only fully processed mature anti-CRPs were detectable, although small amounts of unprocessed HT186-D11n and HT186-D11s scFvs were identified (Figure 4A, compare Figure 1), indicating that the moment of sampling small amounts of untransported protein were still in the cytoplasm. The ratio of processed:unprocessed polypeptide did not seem to correlate with expression levels, since unprocessed protein was

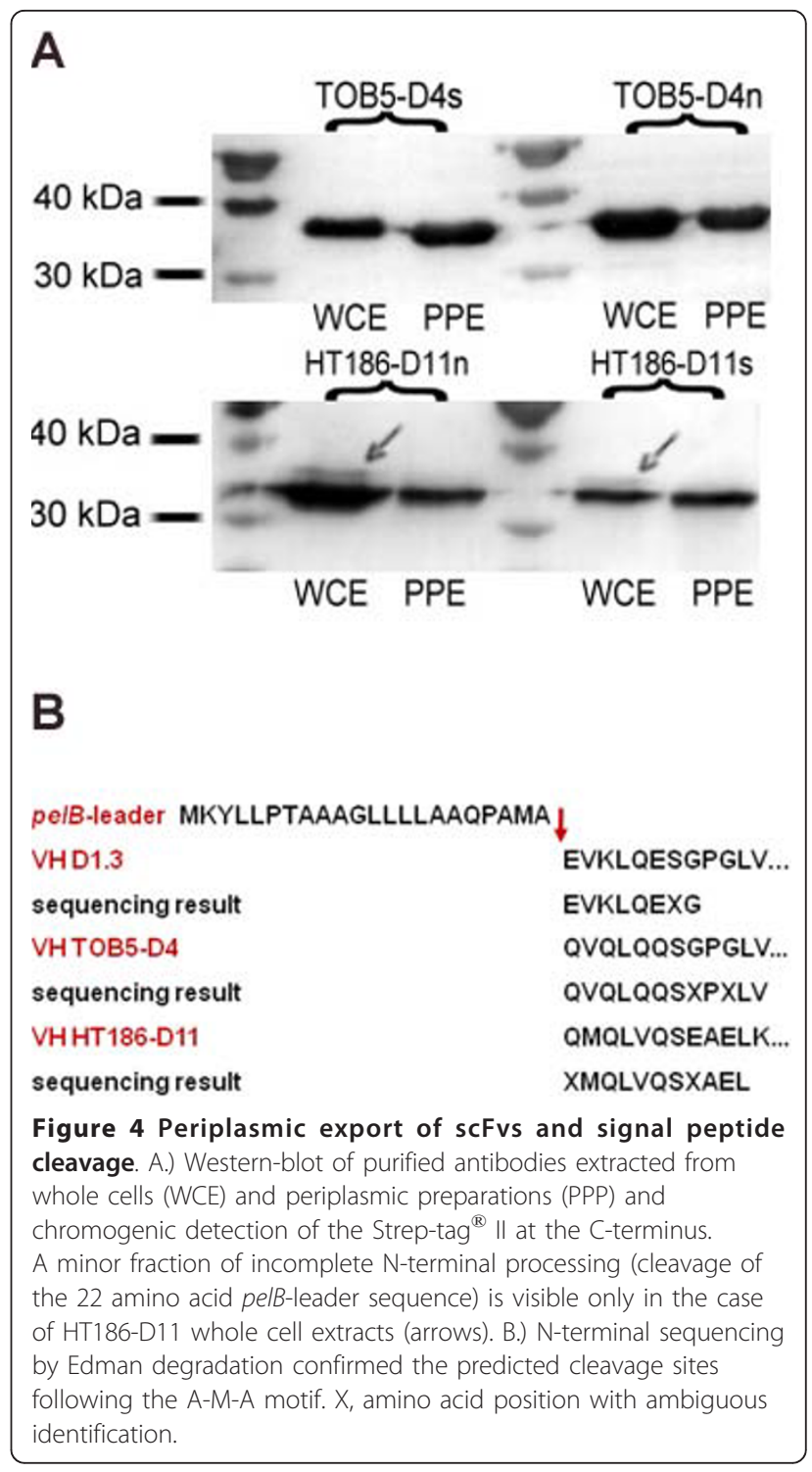

also observed in cells carrying the lower expressing HT186-D11s construct. More likely is the possibility that the $\mathrm{VH}$-coding amino acid sequence affects the secondary structure around the cleavage junction and negatively impacts on the efficiency of processing. The variable yields in periplasmic extracts probably reflect incomplete disruption of the outer membrane by the procedure we used, but might also result from partial non-specific leakage of periplasmic proteins to the medium, a phenomenon previously observed for antibody fragments exported by means of the PelB leader peptide in E. coli [32]. It should, nevertheless, be emphasized that this procedure for selective isolation of periplasmic proteins has the major advantage of yielding active, soluble antibody fragments uncontaminated by cytoplasmic proteins.

The signal peptide cleavage sites of the recombinant scFvs were predicted by means of the in silico tool 
Predisi [33] to be located between amino acids 22 and 23 , directly after the A-M-A motif, which is also the preferred sequence motif (A-X-A) for interaction with signal peptidase I [34], and experimentally confirmed by $\mathrm{N}$-terminal sequencing of isolated antibody (Figure 4B). Other sites of cleavage were not detected, which indicates that the KT2440 LepB peptidase (PP_1432), which shares $39 \%$ amino acid identity and 52\% similarity with the E. coli $\mathrm{K}-12$ peptidase, precisely recognizes and cleaves the PelB processing site.

\section{Antibody activity}

In order to assess whether the extracted periplasmic scFv polypeptides were correctly folded and had acquired correct binding activity, the binding of the TOB5-D4 and HT186-D11 antibodies to their cognate antigens were measured by ELISA assays using plates coated with 100 ng per well of either CRP antigen (BiosPacific, Emeryville, USA), MUC1 32 aa peptide with a C-terminal cysteine (APDTRPAPGSTAPPAHGVTSAPDTRPAPGSTA-C) [21], or bovine serum albumin (BSA; controls). A primary mice anti-Myc-tag IgG, combined with a secondary Fab-specific goat anti-mice IgG horseradish peroxidase (HRP) conjugate were used for detection of bound antibody, as previously described [35]. As can be seen in Figure 5, high specific antigen binding was observed for both recombinant scFvs, with significant signals recorded till antibody concentrations of $10 \mathrm{nM}$, which corresponds to dilutions of $1: 256$, for an antibody having an initial concentration of $2.5 \mu \mathrm{M}$. Recombinant anti-CRP antibody preparations obtained from both whole cells and periplasmic extracts had similar binding activities (data not shown), which is consistent with the findings shown in Figure 4A and the correct folding of periplasmic antibody.

\section{Conclusions}

We have presented here an assessment of the potential of Pseudomonas putida KT2440 as a cell factory for the production of soluble recombinant antibody fragments that bind to antigens of high interest for diagnostics and therapy. With the described construct design, good yields of soluble, active scFvs are obtained through simple extraction of periplasmic polypeptides and single step affinity purification. These yields considerably exceeded those obtained from equivalent constructs in $E$. coli $\mathrm{K}-12$, so KT2440 would seem to be a promising cell factory for recombinant antibody fragment production. It is likely that high density fed-batch cultivation of KT2440 [36], which are typically characterized by cell densities of up to more than $100 \mathrm{~g} / \mathrm{l}$, will allow achievement of much higher yields by this host. A common means of optimizing expression levels of recombinant proteins is the use of synthetic genes with host-optimized codon usage. In

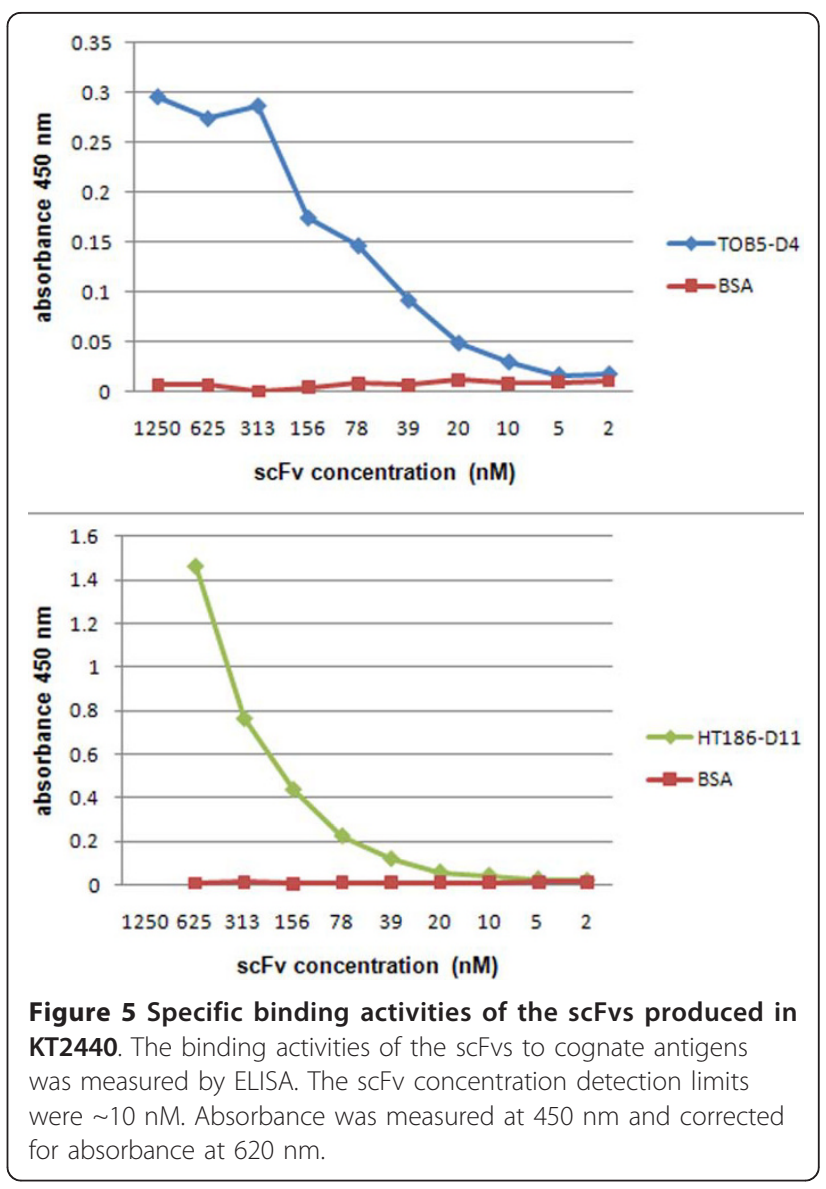

our study, this approach did not achieve increased expression, possibly due to the expression versatility of this host for foreign genes. However, the possibility that a less rigorous adaptation that maintains the $P$. putida KT2440 natural \% G+C value might give better expression would seem worth exploring in future, especially in conjunction with other optimization efforts involving exploration of media and cultivation conditions as well as genetic engineering and genome streamlining approaches. The broad host range feature of the constructs presented here will of course allow their testing in other host systems and potential discovery of even more powerful cell factories for antibody production.

\section{Methods}

\section{Vector construction}

Expression construct pSEVAlacTOB5-D4n was generated by amplification of the $\mathrm{scFv}$ sequence from antibody expression vector pOE101-TOB5-D4 [[11], AlHalabi et al. in preparation], using primers A (fw 5'GCGAATTCTTAACTTTAAGAAGGAGATATATCC ATG A AATACCTATTGCCTACGGC-3') and B (rev 5'-GCTCTAGA TTACTTTTTCGAACTGCGGGTGGC TCCA ATGATGATGGTGATGATGGGATAGATCT 
TC-3') and cloning via EcoRI and XbaI to pSEVA-RK2Sm-lac (pSEVA424). Vector pSEVAlacHT186-D11n was generated amplifying HT186-D11 from phage display vector pHAL14-HT186-D11 [11,21] using primers A and C (5'-GCTCTAGA TTACTTTTCGAACTGCGGG TGCGACCATGCGGCCCCATTCAGATCCTCTTCTG AGATG-3'), and cloning via EcoRI and XbaI into pSEVA-RK2-Sm-lac. Plasmid pSEVAlacD1.3n was constructed using the same primers and restriction sites for the amplification product of pHAL14-D1.3 [11]. Sequences for ribosome binding sites [27], restriction sites and the Strep-tag ${ }^{\circledR}$ II [37] were added with the corresponding primer overlaps.

Vector pSEVAlacTOB5-D4s and pSEVAxylTOB5-D4s were generated using an in silico-designed synthetic construct incorporating the RBS and Strep-tag ${ }^{\circledR}$ II. The sequence was codon-usage adapted to that of $P$. putida KT2440, using Jcat [38], and synthesized by Eurofins MWG (Ebersberg, Germany). The construct was cloned into pSEVA-RK2-Sm-lac and pSEVA-RK2-Sm-XylPm via $M f e I / E c o R I$ and $X b a I$. A synthetic construct was also generated from HT186-D11, codon usage adapted to $P$. putida, and synthesized by GENEART (Regensburg, Germany). Cloning in pSEVA-RK2-Sm-lac and pSEVA-RK2Sm-XylPm via EcoRI/HindIII resulted in pSEVAlacHT186-D11s and pSEVAxylHT186-D11s respectively. All constructs contained the 66 bp Erwinia carotovora pelB-leader sequence for periplasmic export and are summarized in Table 1. E. coli strain DH5 $\alpha$, chemicals and enzymes for PCR and cloning were purchased from Fermentas (St. Leon-Rot, Germany) and New England Biolabs (Ipswich, MA, USA). Integrity of the constructs was verified by sequencing the synthetic construct prior to cloning, and restriction digestion after cloning. Native sequences were amplified from sequence validated templates $[11,21]$, using high fidelity proof-reading polymerase (Phusion ${ }^{\mathrm{TM}}$ ) and confirmed by restriction digestion after cloning.

\section{Transformation of Pseudomonas putida KT2440}

Competent cells were prepared using buffer containing $300 \mathrm{mM}$ sucrose as described before [39]. $30 \mathrm{ng}$ of plasmid constructs were used to transform $40 \mu \mathrm{l}$ of competent $P$. putida KT2440 (DSM 6125) cells by electroporation, which was carried out in prechilled $2 \mathrm{~mm}$ cuvettes using a Gene Pulser II with pulse controller plus and capacitance extender plus (Bio-Rad, Hempel Hempstead, UK). Cell: DNA mixes were pulsed at $2.5 \mathrm{kV}, 25 \mu \mathrm{F}$ and $200-500 \Omega$ resistance, and subsequently plated on selection medium containing $100 \mu \mathrm{g} / \mathrm{ml}$ of streptomycin and spectinomycin.

\section{Production of scFvs with Pseudomonas putida KT2440}

An $50 \mathrm{ml}$ overnight liquid culture of the P. putida KT2440 clone freshly transformed with the respective construct (Table 1) was used to inoculate the production culture 1:100. Production test-cultures were grown in $200 \mathrm{ml}$ cultures at $150 \mathrm{rpm}$ at $\mathrm{RT}, 30^{\circ} \mathrm{C}$ and $37^{\circ} \mathrm{C}$. Luria Bertani (LB) (5 g/l yeast extract, $10 \mathrm{~g} / \mathrm{l}$ tryptone, $10 \mathrm{~g} / \mathrm{l}$ $\mathrm{NaCl})$, rich Luria Bertani Broth (10 g/l yeast extract, $10 \mathrm{~g} / \mathrm{l}$ tryptone, $10 \mathrm{~g} / \mathrm{l} \mathrm{NaCl}$ ), $\mathrm{M} 9$ containing $15 \mathrm{mM}$ succinate, $\mathrm{TB}$, and $\mathrm{R} 2 \mathrm{~A}[40,41]$ containing $50 \mu \mathrm{g} / \mathrm{ml}$ streptomycin were used in $500 \mathrm{ml}$ baffled Erlenmeyer flasks. In the mid logarithmic phase (at $\mathrm{OD}_{595}$ of $\sim 0.5$ 0.6 ), production was induced by addition of isopropyl- $\beta$ D-thiogalactopyranoside (IPTG) at concentrations ranging between $100 \mu \mathrm{M}$ and $1 \mathrm{mM}$, or $15 \mathrm{mM}$ 3-methylbenzoate, for pSEVAxyl-TOB5-D4s and pSEVAxyl-HT186-D11s. Final yields reported in Figure 2 are from lysis of cells cultured in $100 \mathrm{ml} \mathrm{LB}$ at $180 \mathrm{rpm}$ and $30^{\circ} \mathrm{C}$. The cells were harvested by centrifugation.

\section{Production of scFvs in $E$. coli}

To compare yields of recombinant antibody fragments from $P$. putida KT2440 with those from $E$. coli $\mathrm{K}-12$, we introduced the pSEVAlacTOB5-D4 and pSEVAlacHT186-D11 constructs containing the tac promoter

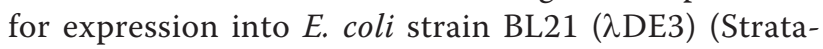
gene). K-12 and KT2440 constructs were cultured at RT for HT186-D11n and $30^{\circ} \mathrm{C}$ for TOB5-D4n with other parameters being as described for KT2440, which in initial experiments also gave the best antibody yields in E. coli.

\section{Periplasmic export and signal peptide cleavage}

To obtain periplasmic extracts, harvested cells were resuspended in PE buffer $(20 \%(\mathrm{w} / \mathrm{v})$ sucrose, $50 \mathrm{mM}$ Tris, $1 \mathrm{mM}$ EDTA, pH 8), incubated for $30 \mathrm{~min}$ on ice with brief vortexing every 5 minutes, and centrifuged at 20,000 rcf for $30 \mathrm{~min}$.

Completeness of signal peptide cleavage was assessed by electrophoresis of antibody fragments on $12.5 \%$ SDSPAGE, semi-dry transfer to PVDF membranes (Peqlab), and anti-Strep-tag detection using Strep-Tactin alkaline phosphatase (AP) conjugate (IBA, Göttingen, Germany) and chromogenic BCIP (5-Bromo-4-Chloro-3'-Indolyphosphate p-Toluidine Salt), NBT (Nitro-Blue Tetrazolium Chloride) detection (AP Blue Membrane Substrate Solution, Sigma). The cleavage position was determined by $\mathrm{N}$-terminal sequencing by Edman degradation and compared to the in silico predicted sites obtained with the Predisi tool [33].

\section{Affinity purification of antibody fragments}

The proteins were obtained by whole cell lysis by sonication in sonication buffer $(50 \mathrm{mM}$ Tris, $100 \mathrm{mM} \mathrm{NaCl}$, $5 \mathrm{mM} \mathrm{MgCl}_{2}, 0,05 \%$ (v/v) Triton X-100, pH 8,0), bacterial protein extraction reagent B-Per (Thermo Fischer scientific) according to the manufacturer's instructions, sonication in B-Per or by periplasmic extraction (see 
below). Whole cell extracts were centrifuged for $15 \mathrm{~min}$ at $15,000 \mathrm{rcf}$ to obtain cell-free extracts which, like periplasmic preparations were applied directly to affinity chromatography columns.

We used IMAC on Ni-TED (Machery-Nagel), for HIStag-based affinity purification, or Strep-Tactin Superflow (IBA) columns for Strep-tag ${ }^{\circledR}$ II-based affinity purification, or both in sequence. The washing and elution procedures were carried out according to the manufacturers' recommendations. Protein concentrations of purified scFv solutions were determined by the method by Gill and van Hippel [42], using the individually calculated molar extinction coefficients for the processed amino acid sequences without signal peptides (Protein Calculator v3.3, http:// www.scripps.edu/ cdputnam/protcalc.html), and the UV absorbance at $280 \mathrm{~nm}$ (protein) and $260 \mathrm{~nm}$ (as control for possible nucleic acid contamination), determined with the NanoDrop ${ }^{\circledR}$ ND-1000 spectrophotometer (Peqlab) or lab spectrometer (Eppendorf).

\section{Antigen binding ELISA}

The antigens, in PBS, were used to coat wells of 96-well microtitre plates (Maxisorp, Nunc). After coating overnight at $4^{\circ} \mathrm{C}$, the wells were washed three times with PBST, and blocked with $2 \%(\mathrm{w} / \mathrm{v})$ skim milk powder in PBST (2\% M-PBST) for $1.5 \mathrm{~h}$ at room temperature, followed by three washes with PBST. For the ELISA, soluble scFvs were diluted in $100 \mu \mathrm{l} 2 \% \mathrm{M}$-PBST and incubated in the antigen-coated plates for $1.5 \mathrm{~h}$ at room temperature, followed by three PBST washes. Bound scFvs were detected with the murine mAb (9E10, Sigma), which recognises the C-terminal c-myc tag, and a goat anti-mouse serum, conjugated with horseradish peroxidase (HRP) (Sigma; 1:10,000). For visualisation the chromogenic substrate 3,3',5,5'-tetramethylbenzidine (TMB) was added. The staining reaction was stopped by addition of $100 \mu \mathrm{l} 1 \mathrm{~N}$ sulphuric acid and absorbance at $450 \mathrm{~nm}$ and $620 \mathrm{~nm}$ was measured using a SUNRISE ${ }^{\mathrm{TM}}$ microtitre plate reader (Tecan, Crailsheim, Germany).

\begin{abstract}
Abbreviations used
aa: amino acid; AP: alkaline phosphatase; RBS: ribosome binding site; CRP: human C-reactive protein; EDTA: ethylenediaminetetraacetic acid; ELISA: enzyme-linked immunosorbent assay; Fab: fragment antigen binding; HRP: horseradish peroxidase; IgG: immunglobulin G; IMAC: immobilized metal ion affinity chromatography; IPTG: isopropyl- $\beta$-D-thiogalactopyranoside; MUC1: human mucin 1; PBS(T): phosphate-buffered saline (tween); PVDF: polyvinylidene fluoride, RPM: rotations per minute; rcf, relative centrifugal force; scFv: single chain fragment variable; $\mathrm{VH}$ : antibody variable domain of the heavy chain; VL: antibody variable domain of the light chain.
\end{abstract}

\section{Acknowledgements}

We are deeply indebted to Prof. V. de Lorenzo (CNB-CSIC Madrid) for providing prototypes of RK2 based pSEVA plasmids. Thanks are also due to $\mathrm{R}$. Getzlaff ( $\mathrm{HZI}$ ) for conducting N-terminal protein sequencing and $\mathrm{B}$. Jung $(\mathrm{HZI})$ for technical assistance. We greatly acknowledge the financial support by the
Federal Ministry of Education and Research to KNT (BMBF, "Psysmo" in the EraNet) and by the German Research Foundation (DFG, SFB 578) to SD.

\section{Author details}

${ }^{1}$ Environmental Microbiology Laboratory, Helmholtz Centre for Infection Research, Inhoffenstr. 7, 38124 Braunschweig, Germany. ${ }^{2}$ Institut für Biochemie und Biotechnologie, Technische Universität Braunschweig, Spielmannstr. 7, 38106 Braunschweig, Germany. ${ }^{3}$ Institut für Mikrobiologie, Technische Universität Braunschweig, Spielmannstr. 7, 38106 Braunschweig, Germany.

\section{Authors' contributions}

TD designed and coordinated the study, drafted the manuscript, performed the experiments with lab support of SCK and analyzed the data. MS conducted the antigen ELISA, MH and SD provided the SCFv sequences, $\mathrm{MH}$, SD and KNT helped to draft the manuscript and to design the study. All authors read and approved the final manuscript.

\section{Competing interests}

$\mathrm{MH}$ and SD are inventors on a patent application regarding anti-MUC1 antibodies (PCT/EP2009/005218). This does not alter our adherence to all the Microbial Cell Factories policies on sharing data and materials. The other authors declare that they have no competing interests.

Received: 14 January 2011 Accepted: 21 February 2011 Published: 21 February 2011

\section{References}

1. Dübel S: Recombinant therapeutic antibodies. Applied Microbiology and Biotechnology 2007, 74:723-729.

2. Dübel S, Stoevesandt O, Taussig MJ, Hust M: Generating recombinant antibodies to the complete human proteome. Trends in Biotechnology 2010, 28:333-339.

3. Hoet RM, Cohen EH, Kent RB, Rookey K, Schoonbroodt S, Hogan S, Rem L, Frans N, Daukandt M, Pieters $H$, et al: Generation of high-affinity human antibodies by combining donor-derived and synthetic complementaritydetermining-region diversity. Nature Biotechnology 2005, 23:344-348.

4. Hust M, Dübel $S$ : Mating antibody phage display with proteomics. Trends in biotechnology 2004, 22:8-14.

5. Thie H, Meyer T, Schirrmann T, Hust M, Dübel S: Phage display derived therapeutic antibodies. Current Pharmaceutical Biotechnology 2008, 9:439-446

6. Schirrmann T, Al-Halabi L, Dübel S, Hust M: Production systems for recombinant antibodies. Frontiers in Bioscience 2008, 13:4576-4594.

7. Hust M, Maiss E, Jacobsen HJ, Reinard T: The production of a genusspecific recombinant antibody ( $\mathrm{scFv}$ ) using a recombinant potyvirus protease. Journal of virological methods 2002, 106:225-233.

8. Meyer T, Stratmann-Selke J, Meens J, Schirrmann T, Gerlach GF, Frank R, Dübel S, Strutzberg-Minder K, Hust M: Isolation of scFv fragments specific to OmpD of Salmonella Typhimurium. Veterinary Microbiology 2011, 10(12):162-9, 147

9. Skerra A, Pfitzinger I, Pluckthun A: The functional expression of antibody Fv fragments in Escherichia coli: improved vectors and a generally applicable purification technique. Biotechnology (N Y) 1991, 9:273-278.

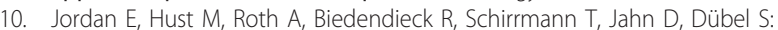
Production of recombinant antibody fragments in Bacillus megaterium. Microbial cell factories 2007, 6:2-2.

11. Hust M, Steinwand M, Al-Halabi L, Helmsing S, Schirrmann T, Dübel S: Improved microtitre plate production of single chain Fv fragments in Escherichia coli. New Biotechnology 2009, 25:424-428.

12. Timmis KN: Pseudomonas putida: a cosmopolitan opportunist par excellence. Environ Microbiol 2002, 4:779-781.

13. Bagdasarian M, Lurz R, Ruckert B, Franklin FC, Bagdasarian MM, Frey J, Timmis KN: Specific-purpose plasmid cloning vectors. II. Broad host range, high copy number, RSF1010-derived vectors, and a host-vector system for gene cloning in Pseudomonas. Gene 1981, 16:237-247.

14. Nelson KE, Weinel C, Paulsen IT, Dodson RJ, Hilbert H, Martins dos Santos VA, Fouts DE, Gill SR, Pop M, Holmes M, et al: Complete genome sequence and comparative analysis of the metabolically versatile Pseudomonas putida KT2440. Environ Microbiol 2002, 4:799-808. 
15. de Lorenzo V, Herrero M, Jakubzik U, Timmis KN: Mini-Tn5 transposon derivatives for insertion mutagenesis, promoter probing, and chromosomal insertion of cloned DNA in gram-negative eubacteria. $J$ Bacteriol 1990, 172:6568-6572

16. Hust M, Jostock T, Menzel C, Voedisch B, Mohr A, Brenneis M, Kirsch MI, Meier D, Dübel S: Single chain Fab (scFab) fragment. BMC biotechnology 2007, 7:14-14.

17. Jordan E, Al-Halabi L, Schirrmann T, Hust M, Dübel S: Production of single chain Fab (scFab) fragments in Bacillus megaterium. Microb Cell Fact 2007, 6:38-38

18. Kirsch M, Zaman M, Meier D, Dübel S, Hust M: Parameters affecting the display of antibodies on phage. Journal of immunological methods 2005, 301:173-185.

19. Thie H, Binius S, Schirrmann T, Hust M, Dübel S: Multimerization domains for antibody phage display and antibody production. New Biotechnology 2009, 26:314-321.

20. Genest J: C-reactive protein: risk factor, biomarker and/or therapeutic target? The Canadian Journal of Cardiology 2010, 26(Suppl A), 41A-44A$41 \mathrm{~A}-44 \mathrm{~A}$.

21. Thie H, Toleikis $L$, Li J, von Wasielewski R, Bastert G, Schirrmann T, Esteves IT, Behrens CK, Fournes B, Fournier N, et al: Rise and Fall of an Anti-MUC1 Specific Antibody. PLOS ONE 2011, 6:e15921.

22. Henderikx P, Neer NC-v, Jacobs A, Linden Evd, Arends JW, Müllberg J, Hoogenboom HR: A human immunoglobulin G1 antibody originating from an in vitro-selected Fab phage antibody binds avidly to tumorassociated MUC1 and is efficiently internalized. The American Journal of Pathology 2002, 160:1597-1608.

23. Schoonooghe S, Burvenich I, Vervoort L, Vos FD, Mertens N, Grooten J: $\mathrm{PH} 1$-derived bivalent bibodies and trivalent tribodies bind differentially to shed and tumour cell-associated MUC1. Protein Engineering, Design \& Selection: PEDS 2010, 23:721-728.

24. de Boer HA, Comstock LJ, Vasser M: The tac promoter: a functional hybrid derived from the trp and lac promoters. Proc Natl Acad Sci USA 1983, $80: 21-25$.

25. Franklin FC, Bagdasarian M, Bagdasarian MM, Timmis KN: Molecular and functional analysis of the TOL plasmid pWWO from Pseudomonas putida and cloning of genes for the entire regulated aromatic ring meta cleavage pathway. Proc Natl Acad Sci USA 1981, 78:7458-7462.

26. Gallegos MT, Marques S, Ramos JL: Expression of the TOL plasmid xylS gene in Pseudomonas putida occurs from a alpha 70-dependent promoter or from alpha 70- and alpha 54-dependent tandem promoters according to the compound used for growth. J Bacteriol 1996, 178:2356-2361.

27. Olins $\mathrm{PO}$, Rangwala $\mathrm{SH}$ : A novel sequence element derived from bacteriophage T7 mRNA acts as an enhancer of translation of the lacZ gene in Escherichia coli. J Biol Chem 1989, 264:16973-16976.

28. Lei SP, Lin HC, Wang SS, Callaway J, Wilcox G: Characterization of the Erwinia carotovora pelB gene and its product pectate lyase. J Bacteriol 1987, 169:4379-4383.

29. Bird RE, Hardman KD, Jacobson JW, Johnson S, Kaufman BM, Lee SM, Lee T, Pope SH, Riordan GS, Whitlow M: Single-chain antigen-binding proteins. Science 1988, 242:423-426.

30. Griswold KE, Mahmood NA, Iverson BL, Georgiou G: Effects of codon usage versus putative $5^{\prime}$-mRNA structure on the expression of Fusarium solani cutinase in the Escherichia coli cytoplasm. Protein Expr Purif 2003, 27:134-142.

31. Jordan $E$, Al-Halabi L, Schirrmann T, Hust M, Dubel S: Production of single chain Fab (scFab) fragments in Bacillus megaterium. Microb Cell Fact 2007, 6:38.

32. Georgiou G, Segatori L: Preparative expression of secreted proteins in bacteria: status report and future prospects. Curr Opin Biotechnol 2005 16:538-545.

33. Hiller K, Grote A, Scheer M, Munch R, Jahn D: PrediSi: prediction of signal peptides and their cleavage positions. Nucleic Acids Res 2004, 32: W375-379.

34. Pugsley AP: The complete general secretory pathway in gram-negative bacteria. Microbiol Rev 1993, 57:50-108.

35. Schirrmann T, Hust M: Construction of human antibody gene libraries and selection of antibodies by phage display. Methods in Molecular Biology (Clifton, NJ) 2010, 651:177-209.
36. Sun Z, Ramsay JA, Guay M, Ramsay BA: Automated feeding strategies for high-cell-density fed-batch cultivation of Pseudomonas putida KT2440. Appl Microbiol Biotechnol 2006, 71:423-431.

37. Schmidt TG, Skerra A: The Strep-tag system for one-step purification and high-affinity detection or capturing of proteins. Nat Protoc 2007, 2:1528-1535

38. Grote A, Hiller K, Scheer M, Munch R, Nortemann B, Hempel DC, Jahn D: JCat: a novel tool to adapt codon usage of a target gene to its potential expression host. Nucleic Acids Res 2005, 33:W526-531.

39. Thomas AW, Topping AW, Slater JH, Weightman AJ: Localization and functional analysis of structural and regulatory dehalogenase genes carried on DEH from Pseudomonas putida PP3. J Bacteriol 1992, 174:1941-1947.

40. Sambrook FaM: Molecular Cloning: A Laboratory Manual Cold Spring Harbor, N.Y.: Cold Spring Harbor Laboratory; 1989.

41. Reasoner DJ, Geldreich EE: A new medium for the enumeration and subculture of bacteria from potable water. Appl Environ Microbiol 1985, 49:1-7.

42. Gill SC, von Hippel PH: Calculation of protein extinction coefficients from amino acid sequence data. Anal Biochem 1989, 182:319-326.

doi:10.1186/1475-2859-10-11

Cite this article as: Dammeyer et al:: Efficient production of soluble recombinant single chain Fv fragments by a Pseudomonas putida strain KT2440 cell factory. Microbial Cell Factories 2011 10:11.

\section{Submit your next manuscript to BioMed Central and take full advantage of:}

- Convenient online submission

- Thorough peer review

- No space constraints or color figure charges

- Immediate publication on acceptance

- Inclusion in PubMed, CAS, Scopus and Google Scholar

- Research which is freely available for redistribution

Submit your manuscript at www.biomedcentral.com/submit
C) Biomed Central 